International Journal of Pure and Applied Mathematics

Volume 114 No. 4 2017, 835-850

ISSN: 1311-8080 (printed version); ISSN: 1314-3395 (on-line version)

url: http://www.ijpam.eu

doi: 10.12732 /ijpam.v114i4.13

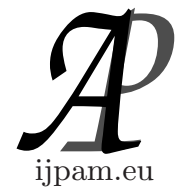

\title{
SOME COMMON FIXED POINT THEOREMS IN 0-COMPLETE PARTIAL ORDERED METRIC SPACES FOR CONTRACTIVE TYPE MAPPINGS
}

\author{
Sudheer Petwal ${ }^{1} \S$, R.C. Dimri ${ }^{2}$ \\ ${ }^{1,2}$ Department of Mathematics \\ H.N.B. Garhwal University \\ Srinagar, 246174, INDIA
}

\begin{abstract}
In this paper, we prove some common fixed point theorems in 0-complete partial ordered metric spaces using contractive condition given by Singh [18]. Our results extend, generalize and unify some of the well known previous results in partial ordered metric spaces.
\end{abstract}

AMS Subject Classification: 47H10, 54H25

Key Words: common fixed point, partial metric space, ordered set, weakly compatible maps, weakly isotone increasing maps

\section{Introduction and Preliminaries}

Banach [3] contraction mapping principle is one of the pivotal results of analysis. It is widely considered as the source of metric fixed point theory and its significance lies in its vast applicability in a number of branches of mathematics. In 1992, Matthews [7] introduced partial metric spaces wherein the distance of a point from itself may not be zero. After introducing the idea of partial metric spaces, Matthews proved the partial metric version of the Banach fixed point theorem. Thereafter, many researchers further studied partial metric spaces and their topological properties which are followed by Veltro, Oltra [12], Valero [20], and Altun and Acar [1], Altun and Sola [2], wherein researchers obtained some generalizations of the core result of Matthews [7].

Received: January 31, 2017

Revised: $\quad$ May 17, 2017

Published: June 7, 2017

$\S$ Correspondence author (c) 2017 Academic Publications, Ltd. url: www.acadpubl.eu 
On the other hand, fixed point theory has developed rapidly in partially ordered metric spaces. The first result in this direction was given by Ran and Reurings [15], who used its applications to matrix equations. Subsequently, Nietro and Rodriguez-Lopez [11] extended this result and applied it to obtain a unique solution for periodic boundary value problems. Further results were obtained by several other authors. The aim of this paper is to generalize the some of the well known previous results in partial ordered metric spaces.

Definition 1. A partial metric on a nonempty set $X$ is a function $p$ : $X \times X \rightarrow R^{+}$such that for all $x, y, z \in X$ :

$\left(p_{1}\right) x=y \Leftrightarrow p(x, x)=p(x, y)=p(y, y)$,

$\left(p_{2}\right) p(x, x) \leq p(x, y)$,

$\left(p_{3}\right) p(x, y)=p(y, x)$,

$\left(p_{4}\right) p(x, y) \leq p(x, z)+p(z, y)-p(z, z)$,

A partial metric space is a pair $(X, p)$ such that $X$ is a nonempty set and $p$ is a partial metric on $X$. Each partial metric $p$ on $X$ generates a $T_{0}$ topology $T_{p}$ on $X$ whose base is the family of open $p$-balls $\left\{B_{p}(x, \epsilon), x \in X, \epsilon>0\right\}$, where $\left\{B_{p}(x, \epsilon)=\{y \in X: P(x, y)<P(x, x)+\epsilon\}\right.$, for all $x \in X$ and $\epsilon>0$.

If $p$ is a partial metric on $X$, then the function $p^{s}: X \times X \rightarrow R^{+}$is given by $p^{s}(x, y)=2 p(x, y)-p(x, x)-p(y, y)$ is a metric on $X$. From $\left(p_{1}\right)$ and $\left(p_{2}\right)$, it is clear that $p(x, y)=0$ then $x=y$ but if $x=y$, then $p(x, y)$ may not be 0 .

Definition 2. A mapping $f: X \rightarrow X$ is said to continuous at $x_{0} \in X$, if for every $\epsilon>0$, there exists $\delta>0$ such that $f\left(B_{p}\left(x_{0}, \delta\right)\right) \subseteq B_{p}\left(f\left(x_{0}\right), \epsilon\right)$.

Remark 2.1. Clearly, a limit of a sequence in a partial metric space need not be unique. Moreover, $p(.,$.$) need not be continuous in the sense that x_{n} \rightarrow x$ and $y_{n} \rightarrow y$ imply $p\left(x_{n}, y_{n}\right) \rightarrow p(x, y)$.

If $p$ is a partial on $X$, then the function $p^{s}: X \times X \rightarrow R^{+}$given by $p^{s}(x, y)=$ $2 p(x, y)-p(x, x)-p(y, y)$ is a metric on $X$. Furthermore, $\lim _{n \rightarrow \infty} p^{s}\left(x_{n}, x\right)=0$ iff $p(x, x)=\lim _{n \rightarrow \infty} p\left(x_{n}, x\right)=\lim _{m, n \rightarrow \infty} p\left(x_{n}, y_{n}\right)$.

Examples. ( $i)$ A paradigmatic example of a partial metric space is the pair $\left(R^{+}, p\right)$, where $p(x, x)=\max \{x, y\}$ for all $x, y \in R^{+}$. The corresponding metric is

$$
p^{s}(x, x)=2 \max \{x, y\}-x-y=|x-y| .
$$

(ii) If $(X, d)$ is a metric space and $c \geq 0$ is arbitrary, then

$$
p(x, y)=d(x, y)+c .
$$

Defines a partial metric on $X$ and the corresponding metric is $p^{s}(x, x)=$ $2 d(x, y)$. 
(iii) $p^{s}: X \times X \rightarrow R^{+}$s.t. $(x, y) \rightarrow p^{s}(x, y)=2 p(x, y)-p(x, x)-p(y, y)=$ $x+y-2 \min \{x, y\}=|x-y|$.

Remark 2.2. If $T: X \rightarrow X$ is continuous at $x_{0} \in X$, then for each sequence $\left\{x_{n}\right\}$ in $X$, we have

$$
\begin{gathered}
x_{n} \rightarrow x_{0} \Rightarrow T x_{n} \rightarrow T x_{0} \text { i.e } \\
p\left(x_{n}, x_{0}\right) \rightarrow p\left(x_{0}, x_{0}\right) \Rightarrow p\left(T x_{n}, T x_{0}\right) \rightarrow p\left(T x_{0}, T x_{0}\right) .
\end{gathered}
$$

Definition 3. Let $(X, p)$ be a partial metric space and $\left\{x_{n}\right\}$ a sequence in $X$. Then:

(a) $\left\{x_{n}\right\}$ converges to a point $x \in X$ if $\lim _{n \rightarrow \infty} p\left(x, x_{n}\right)=p(x, x)$.

(b) $\left\{x_{n}\right\}$ is called a Cauchy sequence if $\lim _{n, m \rightarrow \infty} p\left(x_{n}, x_{m}\right)$ exists and is finite.

Moreover, if $\lim _{n, m \rightarrow \infty} p\left(x_{n}, x_{m}\right)=0$, then $\left\{x_{n}\right\}$ is said to be a 0-Cauchy sequence in $(X, p)$.

Definition 4. A partial metric space $(X, p)$ is said to be 0-complete if every Cauchy sequence $\left\{x_{n}\right\}$ in $X$ converges with respect to $T_{p}$, to a point $x \in X$ such that $p(x, x)=\lim _{n, m \rightarrow \infty} p\left(x_{n}, x_{m}\right)$.

Lemma 1. Let $(X, d)$ be a partial metric space, then:

(i) $\left\{x_{n}\right\}$ is called a Cauchy sequence in $(X, p)$ iff it is Cauchy sequence in the metric space $\left(X, p^{s}\right)$.

(ii) The space $(X, p)$ is complete iff the metric space $\left(X, p^{s}\right)$ is complete.

(iii) If $\left\{x_{n}\right\} \subset X, x_{n} \rightarrow z$ as $n \rightarrow \infty$ and $p(z, z)=0$, then $\lim _{n \rightarrow \infty} p\left(x, x_{n}\right)=$ $p(x, z)$.

$(i v)$ If $(X, d)$ is complete, then it is 0-complete.

$(v)$ A 0-Cauchy sequence in $(X, d)$ is a Cauchy sequence in $\left(X, p^{s}\right)$.

Definition 5. Let $(X, \preceq)$ be a partially ordered set. Then:

(i) Elements $x, y \in X$ are called comparable if $x \preceq y$ or $y \preceq x$ holds;

(ii) A subset $K$ of $X$ is said to be well ordered if every two elements of $K$ are comparable.

(iii) A mapping $T: X \rightarrow X$ is called nondecreasing (nonincreasing) w.r.t $\preceq$ if $x \preceq y$ implies $T x \preceq T y(T x \succeq T y)$.

Definition 6. Let $X$ be a nonempty set. Then $(X, p, \preceq)$ is called an ordered (partial) metric space if:

(i) $(X, p)$ is a partial metric space, and

(ii) $(X, \preceq)$ is a partially ordered set. 
Definition 7. Let $(X, p, \preceq)$ be an ordered partial metric space. We say that $X$ is regular if the following holds: if $\left\{z_{n}\right\}$ is a nondecreasing (nonincreasing) sequence in $X$ with respect to $\preceq$ such that $z_{n} \rightarrow z \in X$ as $n \rightarrow \infty$,then $z_{n} \preceq z\left(z_{n} \succeq z\right)$ for all $n \in N$.

In this paper, we first prove a fixed point theorem for a monotone self-map in a 0-complete partially ordered metric space under Singh [18] type contractive condition. The Theorem (3.2) is concerned with two weakly isotone increasing self-mappings in ordered partial metric spaces. We establish the Theorem 3.3 using the concept of weakly compatible mappings for four mappings in partially ordered metric spaces.

\section{Main Results}

Theorem 8. Let $(X, p, \preceq)$ be a 0-complete ordered partial metric space. Let $f: X \rightarrow X$ be a nondecreasing (nonincreasing) mapping such that

$$
p\left(f^{p} x, f^{p} y\right) \leq a\left[p\left(x, f^{p} x\right)+p\left(y, f^{p} y\right)\right]
$$

for all comparable $x, y \in X$, where $a \in(0,1 / 2)$ and $p$ is some positive integer.

Suppose that there exists $x_{0} \in X$ with $x_{0} \preceq f^{p} x_{0}$ (respectively $x_{0} \succeq f^{p} x_{0}$ ). Suppose that

(i) $f$ is continuous, or

(ii) $X$ is regular.

Then $f$ has a unique fixed point $z$ and $p(f z, f z)=0=p(z, z)$. Moreover, the set $F(T)$ of fixed points of $f$ is well ordered if and only if it is a singleton.

Proof. We prove the theorem for the case of a nondecreasing mapping. Let $x_{0} \in X$ be arbitrary. Define a sequence $\left\{x_{n}\right\}$ in $X$ such that $x_{n}=f^{p} x_{n-1}$, for all $n \in N$. If $p\left(x_{n}, x_{n+1}\right)=0$ for some $n \geq 0$, then $f^{p} x_{n}=x_{n+1}=x_{n}$ and $p\left(x_{n}, x_{n}\right)=0$. Proof is completed.

Suppose that $p\left(x_{n}, x_{n+1}\right) \geq 0$ for all $n \geq 0$. Note that, $f$ is nondecreasing, we have that $x_{0} \preceq f^{p} x_{0}=x_{1} \preceq f^{p} x_{1}=x_{2} \preceq \cdots x_{n} \preceq f^{p} x_{n}=x_{n+1} \preceq f^{p} x_{n+1} \preceq$ ․ applying condition (1) to comparable elements $x=x_{n}$ and $y=x_{n+1}$, we get

$$
\begin{gathered}
p\left(x_{n+1}, x_{n+2}\right)=p\left(f^{p} x_{n}, f^{p} x_{n+1}\right) \leq a\left[p\left(x_{n}, f^{p} x_{n}\right)+p\left(x_{n+1}, f^{p} x_{n+1}\right)\right] \\
=a\left[p\left(x_{n}, x_{n+1}\right)+p\left(x_{n+1}, x_{n+2}\right]\right. \\
p\left(x_{n+1}, x_{n+2}\right) \leq \frac{a}{1-a} p\left(x_{n}, x_{n+1}\right) .
\end{gathered}
$$


Let $\frac{a}{1-a}=k$ (say), then

$$
\begin{gathered}
p\left(x_{n+1}, x_{n+2}\right) \leq k p\left(x_{n}, x_{n+1}\right) \\
\leq \cdots
\end{gathered}
$$

In this way, we get

$$
p\left(x_{n+1}, x_{n+2}\right) \leq k^{n} p\left(x_{n}, x_{n+1}\right) .
$$

Next to claim that $\left\{x_{n}\right\}$ is a Cauchy sequence, consider $m, n \in N$ such that $m>n$. Now

$$
\begin{gathered}
p\left(x_{n}, x_{m}\right) \leq p\left(x_{n}, x_{n+1}\right)+p\left(x_{n+1}, x_{n+2}\right) \leq \cdots p\left(x_{m-1}, x_{m}\right) \\
\leq k^{n} p\left(x_{0}, x_{1}\right)+k^{n+1} p\left(x_{0}, x_{1}\right)+\cdots+k^{m-1} p\left(x_{0}, x_{1}\right) \\
\leq k^{n} p\left(x_{0}, x_{1}\right)+k^{n+1} p\left(x_{0}, x_{1}\right)+\cdots+k^{m-1} p\left(x_{0}, x_{1}\right)+\cdots \\
\leq \frac{k^{n}}{1-k} p\left(x_{0}, x_{1}\right) .
\end{gathered}
$$

Since $k \in(0,1)$, we get $\frac{k^{\mathrm{n}}}{1-k} \rightarrow 0$ as $n \rightarrow \infty$. Hence $\lim _{m, n \rightarrow \infty} p\left(x_{n}, x_{m}\right)=0$. Therefore $\left\{x_{n}\right\}$ is a 0 -Cauchy sequence in $(X, p)$. Since $(X, p)$ is complete, it follows that there exists $z \in X$ s.t. $x_{n} \rightarrow z$ in $(X, p)$ and $p(z, z)=0$. Moreover,

$$
\lim _{n \rightarrow \infty} p\left(x_{n}, z\right)=p(z, z)=0 .
$$

Now, we shall prove that $f z=z$.

(i) Suppose that $f$ is continuous. Letting $n \rightarrow \infty$ then

$$
\begin{gathered}
p\left(z, f^{p} z\right) \leq p\left(z, x_{n+1}\right)+p\left(x_{n+1}, f^{p} z\right)-p\left(x_{n+1}, x_{n+1}\right) \\
\leq p\left(z, x_{n+1}\right)+p\left(x_{n+1}, f^{p} z\right) .
\end{gathered}
$$

Using (4), we get

$$
\begin{aligned}
p\left(z, f^{p} z\right) & \leq \lim _{n \rightarrow \infty} p\left(z, x_{n+1}\right)+\lim _{n \rightarrow \infty} p\left(f^{p} x_{n}, f^{p} z\right) \\
& =p(z, z)+p\left(f^{p} z, f^{p} z\right)=p\left(f^{p} z, f^{p} z\right) .
\end{aligned}
$$

Thus, we have

$$
p\left(z, f^{p} z\right) \leq p\left(f^{p} z, f^{p} z\right)
$$

But from $\left(p_{2}\right)$, we have $p(f z, f z) \leq p\left(z, f^{p} z\right)$. Hence $p\left(z, f^{p} z\right)=p\left(f^{p} z, f^{p} z\right)$.

Suppose that $p\left(z, f^{p} z\right)>0$. Since $z \preceq z$ we have

$$
p\left(z, f^{p} z\right) \leq p\left(f^{p} z, f^{p} z\right) \leq a\left[\left(z, f^{p} z\right)+\left(z, f^{p} z\right)\right]
$$




$$
\leq 2 a p\left(z, f^{p} z\right)<p\left(z, f^{p} z\right)
$$

a contradiction. Thus, we get $p\left(f^{p} z, f^{p} z\right)=p\left(z, f^{p} z\right)=0$. From $\left(p_{1}\right)$, we conclude that $z=f^{p} z$; where $p$ is some positive integer and $f$ is continuous. Therefore $z=f z$.

(ii) Suppose now that the space $X$ is regular. Substituting $x=x_{n}$ and $y=z$ (these are comparable elements) in the contractive condition (1), we have

$$
p\left(x_{n+1}, f^{p} z\right)=p\left(f^{p} x_{n}, f^{p} z\right) \leq a\left[p\left(x_{n}, f^{p} x_{n}\right)+p\left(z, f^{p} z\right)\right] .
$$

Passing to the limit as $n \rightarrow \infty$, and using Lemma 1(iii), we get

$$
\begin{gathered}
p\left(z, f^{p} z\right) \leq a\left[p\left(z, f^{p} z\right)+p\left(z, f^{p} z\right)\right] \\
=2 a\left[p\left(z, f^{p} z\right)\right]<p\left(z, f^{p} z\right),
\end{gathered}
$$

which is possible only if $p\left(z, f^{p} z\right)=0$. We conclude that $f^{p} z=z$. Now suppose that the set of fixed points of $f$ is well ordered. We claim that the fixed point of $f$ is unique. Let us suppose that $f^{p} u=u$ and $f^{p} v=v$ but $u \neq v$. Then by (1) we obtain,

$$
\begin{aligned}
p(u, v)=p\left(f^{p}\right. & \left.u, f^{p} v\right) \leq a\left[p\left(u, f^{p} u\right)+p\left(v, f^{p} v\right)\right] \\
& =a[p(u, u)+p(v, v)] \\
& \leq a[p(u, v)+p(v, u)] \\
& \leq 2 a p(u, v)<p(u, v) .
\end{aligned}
$$

Unless $p(u, v)=0$. Hence $u=v$. So fixed point of $f^{p}$ is unique, which implies that fixed point of $f$ is also unique. The converse is trivial. Thus, the proof is complete.

Example 8.1. Let $X=[0,1] \cup\{2\}$ be a set with usual partial metric. Define a function $f$ such that

$$
f(x)= \begin{cases}0, \text { if } & x \in[0,1] \\ 1, \text { if } & x=2\end{cases}
$$

Here $f[0,1]=0$ and $f(2)=1$, we get $f^{2}(x)=f^{3}(x)=\cdots f^{p}(x)=0$; for every $x$. Let $x=0$ and $y=1$. Applying (1), we have

$$
\begin{gathered}
p\left(f^{p} 0, f^{p} 1\right) \leq a\left[p\left(0, f^{p} 1\right)+p\left(1, f^{p} 1\right)\right] \\
p(0,0) \leq a[p(0,0)+p(1,0)] \Rightarrow 0 \leq a=(0,1 / 2) .
\end{gathered}
$$


So, Theorem is verified and $f^{p}(x)$ has a fixed point 0 . Consequently $f$ has also fixed point 0 .

Common fixed point result for pair of weakly isotone increasing mappings

Now we prove a common fixed point theorem for a pair of maps satisfying $g$-weakly isotone increasing property.

Definition 9. Let $(X, \preceq)$ be a partially ordered set, and let $f, g: X \rightarrow X$ be two mappings.

(a) [8] The pair $(f, g)$ is said to be weakly increasing if $f x \preceq g f x$ and $g x \preceq f g x$ for all $x \in X$.

(b) [9] The mapping $f$ is said to be $g$-weakly isotone increasing if for all $x \in X$ we have $f x \preceq g f x \preceq f g f x$.

Remark 9.1. If $f, g: X \rightarrow X$ are weakly increasing then $f$ is $g$-weakly isotone increasing mapping.

Theorem 10. Let $(X, p, \preceq)$ be a 0-complete ordered partial metric space. Let $f, g: X \rightarrow X$ be two maps such that $f$ is $g$-weakly isotone increasing and satisfying

$$
p\left(f^{p} x, g^{p} y\right) \leq a\left[p\left(x, f^{p} x\right)+p\left(y, g^{p} y\right)\right],
$$

for all comparable $x, y \in X$, where $a \in(0,1 / 2)$ and $p$ is some positive integer. We assume that

(i) $f$ and $g$ are continuous, or

(ii) $X$ is regular.

Then $f$ and $g$ have a common fixed point $z$ and $p(f z, f z)=0=p(z, z)=$ $p\left(f^{p} z, f^{p} z\right)=p\left(g^{p} z, g^{p} z\right)=p\left(z, f^{p} z\right)=p\left(z, g^{p} z\right)$. Moreover, the set $F(T)$ of fixed points of $f$ and $g$ is well ordered if and only if $f$ and $g$ have a unique common fixed point.

Proof. Let $x_{0} \in X$ be arbitrary point. If $p\left(x_{0}, f^{p} x_{0}\right)=0$ or $p\left(x_{0}, g^{p} x_{0}\right)=0$, then proof is finished. We assume that $p\left(x_{0}, f^{p} x_{0}\right)>0$ and $p\left(x_{0}, g^{p} x_{0}\right)>0$. Now, we define a sequence $\left\{x_{n}\right\}$ in $X$ such that $x_{2 n+1}=f^{p} x_{2 n}$ and $x_{2 n+2}=$ $g^{p} x_{2 n+1}$ for $n \in N \cup\{0\}$. Note that, since $f$ is $g$ - weakly isotone increasing, we obtain

$$
x_{1}=f^{p} x_{0} \preceq g^{p} f^{p} x_{0}=g^{p} x_{1}=x_{2} \preceq f^{p} g^{p} f^{p} x_{0}=f^{p} g^{p} x_{1}=f^{p} x_{2}=x_{3} .
$$

Continuing this process, we get

$$
x_{1} \preceq x_{2} \preceq x_{1} \preceq \cdots \preceq x_{n} \preceq x_{n+1} \preceq \cdots
$$


Now using (5), for $x=x_{2 n+1}$ and $y=x_{2 n}$, we have

$$
\begin{aligned}
& p\left(x_{2 n}, x_{2 n+1}\right)=p\left(g^{p} x_{2 n-1}, f^{p} x_{2 n}\right) \\
\leq & a\left[p\left(x_{2 n-1}, g^{p} x_{2 n-1}\right)+p\left(x_{2 n}, f^{p} x_{2 n}\right)\right] \\
= & a\left[p\left(x_{2 n-1}, x_{2 n}\right)+p\left(x_{2 n}, x_{2 n+1}\right)\right] \\
& p\left(x_{2 n}, x_{2 n+1}\right) \leq \frac{a}{1-a} p\left(x_{2 n-1}, x_{2 n}\right) .
\end{aligned}
$$

Let $\frac{a}{1-a}=k($ say $)$, then

$$
\begin{aligned}
p\left(x_{2 n}, x_{2 n+1}\right) & \leq k p\left(x_{2 n-1}, x_{2 n}\right) . \\
& \leq \cdots
\end{aligned}
$$

In this way, we get

$$
p\left(x_{2 n}, x_{2 n+1}\right) \leq k^{n} p\left(x_{0}, x_{1}\right) .
$$

Next to claim that $\left\{x_{n}\right\}$ is a Cauchy sequence, consider $m, n \in N$ such that $m>n$. Now

$$
\begin{gathered}
p\left(x_{n}, x_{m}\right) \leq p\left(x_{n}, x_{n+1}\right)+p\left(x_{n+1}, x_{n+2}\right) \leq \cdots p\left(x_{m-1}, x_{m}\right) \\
\leq k^{n} p\left(x_{0}, x_{1}\right)+k^{n+1} p\left(x_{0}, x_{1}\right)+\cdots+k^{m-1} p\left(x_{0}, x_{1}\right) \\
\leq k^{n} p\left(x_{0}, x_{1}\right)+k^{n+1} p\left(x_{0}, x_{1}\right)+\cdots+k^{m-1} p\left(x_{0}, x_{1}\right)+\cdots \\
\leq \frac{k^{n}}{1-k} p\left(x_{0}, x_{1}\right)
\end{gathered}
$$

Since $k \in(0,1)$, we get $\frac{k^{\mathrm{n}}}{1-k} \rightarrow 0$ as $n \rightarrow \infty$. Therefore $\lim _{m, n \rightarrow \infty} p\left(x_{n}, x_{m}\right)=0$. Hence $x_{n}$ is a 0 -Cauchy sequence in $(X, p)$. Since $(X, p)$ is complete, it follows that there exists $z \in X$ s.t. $x_{n} \rightarrow z$ in $(X, p)$ and $p(z, z)=0$. Moreover, $\lim _{n \rightarrow \infty} p\left(x_{n}, z\right)=p(z, z)=0$. Now, we shall prove that $f z=z=g z$. From $\left(p_{4}\right)$, we have

$$
\begin{gathered}
p\left(z, f^{p} z\right) \leq p\left(z, x_{2 n+1}\right)+p\left(x_{2 n+1}, f^{p} z\right)-p\left(x_{2 n+1}, x_{2 n+1}\right) \\
\leq p\left(z, x_{2 n+1}\right)+p\left(x_{2 n+1}, f^{p} z\right) .
\end{gathered}
$$

Similarly

$$
p\left(z, f^{p} z\right) \leq p\left(z, x_{2 n+2}\right)+p\left(x_{2 n+2}, f^{p} z\right) .
$$

(i) Suppose that $f$ is continuous. Letting $n \rightarrow \infty$ in (7), we get

$$
p\left(z, f^{p} z\right) \leq \lim _{n \rightarrow \infty} p\left(z, x_{2 n+1}\right)+\lim _{n \rightarrow \infty} p\left(x_{2 n+1}, f^{p} z\right)=p\left(f^{p} z, f^{p} z\right) .
$$


Thus, we have $p\left(z, f^{p} z\right) \leq p\left(f^{p} z, f^{p} z\right)$. But from $\left(p_{2}\right)$, we have $p(z, z) \leq p(z, x)$. Hence

$$
p\left(z, f^{p} z\right)=p\left(f^{p} z, f^{p} z\right) .
$$

Similarly if $g$ is continuous, we have

$$
p\left(z, f^{p} z\right)=p\left(f^{p} z, f^{p} z\right) .
$$

From $\left(p_{4}\right)$ and using (8), we have

$$
\begin{gathered}
p\left(z, g^{p} z\right) \leq p\left(z, f^{p} z\right)+p\left(f^{p} z, g^{p} z\right)-p\left(f^{p} z, f^{p} z\right) \\
\leq p\left(z, f^{p} z\right)+p\left(f^{p} z, g^{p} z\right)-p\left(z, f^{p} z\right) \\
\leq p\left(f^{p} z, g^{p} z\right) .
\end{gathered}
$$

Similarly from $\left(p_{4}\right)$ and using (9), we can obtain

$$
p\left(z, f^{p} z\right) \leq p\left(f^{p} z, g^{p} z\right) .
$$

Suppose $p\left(f^{p} z, g^{p} z\right)>0$. Then, since $z \preceq z$, by inequality (5), we have

$$
\left(f^{p} z, g^{p} z\right) \leq a\left[p\left(z, f^{p} z\right)+p\left(z, g^{p} z\right)\right] .
$$

Using (10) and (11) in (12), we have

$$
\begin{aligned}
\left(f^{p} z, g^{p} z\right) \leq & a\left[p\left(f^{p} z, g^{p} z\right)+p\left(f^{p} z, g^{p} z\right)\right] \\
& \leq 2 a p\left(f^{p} z, g^{p} z\right)
\end{aligned}
$$

which is a contradiction. Hence $f^{p} z=g^{p} z$. Therefore $z$ is a coincidence point of $f^{p} z$ and $g^{p} z$. Suppose that $p\left(z, f^{p} z\right)>0$. Then

$$
\begin{gathered}
p\left(z, f^{p} z\right)=p\left(f^{p} z, f^{p} z\right)=p\left(f^{p} z, g^{p} z\right) \\
\leq a\left[p\left(z, f^{p} z\right)+p\left(z, g^{p} z\right)\right] \\
\leq a\left[p\left(z, f^{p} z\right)+p\left(z, f^{p} z\right)\right]
\end{gathered}
$$

$\leq 2 a p\left(z, f^{p} z\right)<p\left(z, f^{p} z\right)$, a contradiction. Hence $f^{p} z=z$. This implies that $f^{p} z=g^{p} z=z$. Therefore $z$ is a common fixed point of $f^{p} z$ and $g^{p} z$ for some positive integer $p$. Implying that $z$ is also a common fixed point of $f$ and $g$.

(ii) Since $\left\{x_{n}\right\}$ is a nondecreasing sequence. Suppose that $X$ is regular. It follows that $x_{n} \preceq z$ for all $n$. Therefore, for all $n$, applying (5) for $x_{n+1}$ and $z$. We get

$$
p\left(x_{2 n+1}, z\right)=p\left(f^{p} x_{2 n}, g^{p} z\right) \leq a\left[p\left(x_{2 n}, f^{p} x_{2 n}\right)+p\left(z, g^{p} z\right)\right] .
$$


Passing to the limit as $n \rightarrow \infty$; and using Lemma 1(iii), we get

$$
\begin{gathered}
p\left(f^{p} z, g^{p} z\right) \leq a\left[p\left(z, f^{p} z\right)+p\left(z, g^{p} z\right)\right] . \\
\quad \leq a\left[p\left(f^{p} z, g^{p} z\right)\right]<p\left(f^{p} z, g^{p} z\right),
\end{gathered}
$$

which is possible only if $p\left(f^{p} z, g^{p} z\right)=0$. We conclude that $f^{p} z=g^{p} z$. Now, we have

$$
\begin{gathered}
p\left(z, f^{p} z\right) \leq p\left(z, x_{2 n+2}\right)+p\left(x_{2 n+2}, f^{p} z\right)-p\left(x_{2 n+2}, x_{2 n+2}\right. \\
p\left(z, f^{p} z\right) \leq p\left(z, x_{2 n+2}\right)+p\left(x_{2 n+2}, f^{p} z\right) \\
\leq p\left(z, x_{2 n+2}\right)+p\left(g^{p} x_{2 n+1}, f^{p} z\right) .
\end{gathered}
$$

Passing to the limit as $n \rightarrow \infty$; and using Lemma 1(iii), we obtain

$$
\begin{gathered}
p\left(z, f^{p} z\right) \leq p(z, z)+p\left(f^{p} z, g^{p} z\right)=p\left(f^{p} z, g^{p} z\right) \\
p\left(z, f^{p} z\right) \leq p\left(f^{p} z, f^{p} z\right) .
\end{gathered}
$$

But from $\left(p_{2}\right) ; p(x, x) \leq p(x, y)$, therefore $p\left(z, f^{p} z\right)=0$; it follows that $f^{p} z=z$. Therefore $f^{p} z=g^{p} z=z$. Hence $z$ is a common fixed point of $f$ and $g$. Now suppose that the set of common fixed points of $f^{p}$ and $g^{p}$ is well ordered. We claim that common fixed point of $f^{p}$ and $g^{p}$ is unique. Assume to the contrary that $f^{p} u=g^{p} u=u$ and $f^{p} v=g^{p} v=v$, then by (5), we get

$$
\begin{gathered}
p(u, v)=\left(f^{p} u, g^{p} v\right) \leq a\left[p\left(u, f^{p} u\right)+p\left(v, g^{p} v\right)\right] \\
\leq a[p(u, u)+p(v, v)] .
\end{gathered}
$$

But from $\left(p_{2}\right)$; we have $p(z, z) \leq p(x, z)$. Hence

$$
\begin{gathered}
p(u, v) \leq a[p(u, v)+p(u, v)] \\
p(u, v) \leq 2 a p(u, v)<p(u, v), \text { a contradiction. }
\end{gathered}
$$

Which is a contradiction. Hence $p(u, v)=0$ implies $u=v$. Therefore $f$ and $g$ have unique fixed point. Conversely, if $f$ and $g$ have only one common fixed point i.e set of fixed points of $f$ and $g$ being a singleton then it is well ordered. Thus, the proof is completed.

Example 10.1. Let $X=[0,1] \cup\{2\}$ be a set with usual partial metric. Define two function $f$ and $g$ such that

$$
f(x)= \begin{cases}0, \text { when } & x \in[0,1] \\ 1, \text { when } & x=2\end{cases}
$$




$$
g(x)= \begin{cases}0, \text { when } & x \in[0,1] \\ 1 / 2, \text { when } & x=2\end{cases}
$$

Here $f[0,1]=0$ and $f(2)=1$, we get $f^{2}(x)=f^{3}(x)=\cdots f^{p}(x)=0$; for every $x$, and $g[0,1]=0$ and $g(2)=1 / 2$, we get $g^{2}(x)=g^{3}(x)=\cdots g^{p}(x)=0$; for every $x$. Let $x=0$ and $y=1 / 2$. Applying (5); we have

$$
p\left(f^{p} 0, g^{p} 1 / 2\right) \leq a\left[p\left(0, f^{p} 0\right)+p\left(1 / 2, g^{p} 1 / 2\right)\right]
$$

$p(0,0) \leq a[p(0,0)+p(1 / 2,0)] \Rightarrow 0 \leq \frac{a}{2}$. So, Theorem (3.5) is verified and $f^{p}(x)$ and $g^{p}(x)$ have a common fixed point 0 . Consiquently $f$ and $g$ have a common fixed point 0 .

\section{Common fixed point result for weakly compatible mappings for four maps}

Now we prove a common fixed point theorem for weakly compatible mappings for four maps. To prove this result, we need the following definitions:

Definition 11. [19] Let $(X, \preceq)$ be a partially ordered set, and let $f, g$ : $X \rightarrow X$ be two mappings.

(a) Pair $(f, g)$ are compatible if $\lim _{n} p\left(f g x_{n}, g f x_{n}\right)=0$, whenever $\left\{x_{n}\right\}$ is a sequence in $X$ such that $\lim _{n} f x_{n}=\lim _{n} g x_{n}=z$ for some $z \in X$.

(b) Pair $(f, g)$ are weakly compatible if they commute at their coincidence points, that is $f g z=g f x$, whenever $f x=g x$ for $x \in X$.

(c) Pair $(f, g)$ are $f$-compatible if $\lim _{n} p\left(f g x_{n}, g g x_{n}\right)=0$, whenever $\left\{x_{n}\right\}$ is a sequence in $X$ such that $\lim _{n} f x_{n}=\lim _{n} g x_{n}=z$ for some $z \in X$.

(d) Pair $(f, g)$ are $g$-compatible if $\lim _{n} p\left(g f x_{n}, f f x_{n}\right)=0$, whenever $\left\{x_{n}\right\}$ is a sequence in $X$ such that $\lim _{n} f x_{n}=\lim _{n} g x_{n}=z$ for some $z \in X$.

Theorem 12. Let $(X, p, \preceq)$ be a 0-complete ordered partial metric space. Let $f, g, T$ and $S: X \rightarrow X$ be four maps satisfying

$$
p\left(T^{p} f x, S^{p} g y\right) \leq a\left[p\left(S^{p} x, T^{p} f x\right)+p\left(T^{p} y, S^{p} g y\right)\right]
$$

for all comparable $x, y \in X$. Where $a \in(0,1 / 2)$ and $p$ is some positive integer. We assume that

(i) $f, g, T$ and $S$ are continuous.

(ii) Pair $\left(f, T^{p}\right)$ and $\left(g, S^{p}\right)$ are weakly compatible. Then $f, g, T$ and $S$ have a fixed point $z$ and $p(f z, f z)=0=p(z, z)=p\left(f^{p} z, f^{p} z\right)=p\left(g^{p} z, g^{p} z\right)=$ $p\left(z, f^{p} z\right)=p\left(z, g^{p} z\right)=p\left(T^{p} z, T^{p} z\right)=p\left(z, T^{p} z\right)=p\left(z, S^{p} z\right)=p\left(S^{p} z, S^{p} z\right)$. Moreover, the set $F(T)$ of fixed points of $f, g, T$ and $S$ are well ordered if and only if $f, g, T$ and $S$ have a unique common fixed point. 
Proof. Let $x_{0} \in X$ be an arbitrary point. Now, we construct two iterative sequences $\left\{x_{n}\right\}$ and $\left\{y_{n}\right\}$ in the following way:

$y_{2 n+1}=T^{p} x_{2 n+1}, y_{2 n+2}=S^{p} x_{2 n+2}, x_{2 n+1}=f x_{2 n}$ and $x_{2 n+2}=g x_{2 n+1}$. Now, since $x=x_{2 n-1}$ and $y=x_{2 n}$ are comparable. Applying (14) for these points, we have

$$
\begin{gathered}
p\left(y_{2 n+1}, y_{2 n+2}\right)=p\left(T^{p} x_{2 n+1}, S^{p} x_{2 n+2}\right)=p\left(T^{p} f x_{2 n}, S^{p} g x_{2 n+1}\right) \\
\leq a\left[p\left(S^{p} x_{2 n}, T^{p} f x_{2 n}\right)+p\left(T^{p} x_{2 n+1}, S^{p} g x_{2 n+1}\right)\right] \\
\leq a\left[p\left(y_{2 n}, y_{2 n+1}\right)+p\left(y_{2 n+1}, y_{2 n+2}\right)\right] \\
\leq \frac{a}{1-a}\left[p\left(y_{2 n}, y_{2 n+1}\right)\right]
\end{gathered}
$$

Let $\frac{a}{1-a}=k$; then

$$
\begin{gathered}
p\left(y_{2 n+1}, y_{2 n+2}\right) \leq k p\left(y_{2 n}, y_{2 n+1}\right) \\
\leq \cdots \\
p\left(y_{2 n+1}, y_{2 n+2}\right) \leq k^{n} p\left(y_{2 n}, y_{2 n+1}\right) .
\end{gathered}
$$

Here $k \in(0,1)$ and $n \rightarrow \infty$.Then $\lim _{n \rightarrow \infty} p\left(y_{2 n+1}, y_{2 n+2}\right)=0$. Next to claim that $\left\{y_{n}\right\}$ is a Cauchy sequence, consider $m, n \in N$ such that $m>n$. Now;

$$
\begin{gathered}
p\left(y_{n}, y_{m}\right) \leq p\left(y_{n}, y_{n+1}\right)+p\left(y_{n+1}, y_{n+2}\right) \leq \cdots p\left(y_{m-1}, y_{m}\right) \\
\leq k^{n} p\left(y_{0}, y_{1}\right)+k^{n+1} p\left(y_{0}, y_{1}\right)+\cdots+k^{m-1} p\left(y_{0}, y_{1}\right) \\
\leq k^{n} p\left(y_{0}, y_{1}\right)+k^{n+1} p\left(y_{0}, y_{1}\right)+\cdots+k^{m-1} p\left(y_{0}, y_{1}\right)+\cdots \\
\leq \frac{k^{n}}{1-k} p\left(y_{0}, y_{1}\right) .
\end{gathered}
$$

Since $k \in(0,1)$, we get $\frac{k^{\mathrm{n}}}{1-k} \rightarrow 0$ as $n \rightarrow \infty$. Therfore $\lim _{m, n \rightarrow \infty} p\left(y_{n}, y_{m}\right)=0$. Hence $\left\{y_{n}\right\}$ is a 0 -Cauchy sequence in $(X, P)$. Since $(X, p)$ is a complete, it follows that there exists $z \in X$ s.t. $y_{n} \rightarrow z$ in $(X, p)$ and $p(z, z)=0$. Moreover

$$
\lim _{n \rightarrow \infty} p\left(y_{n}, z\right)=p(z, z)=0 .
$$

Now, we shall prove that $f z=g z=T z=S z$. It follows that $\left\{y_{n}\right\}$ is a Cauchy sequence and since $X$ is complete, there exists a point $z$ in $X$, such that $y_{n}$ converges to $z$, also we assume that pair $\left(f, T^{p}\right)$ and $\left(g, S^{p}\right)$ are weakly compatible. Therefore

$$
\left[\lim _{n \rightarrow \infty} y_{2 n+1}=\lim _{n \rightarrow \infty} T^{p} x_{2 n+1}=z=\lim _{n \rightarrow \infty} y_{2 n+2}=\lim _{n \rightarrow \infty} S^{p} x_{2 n+2},\right.
$$




$$
\begin{gathered}
\lim _{n \rightarrow \infty} x_{2 n+1}=\lim _{n \rightarrow \infty} f x_{2 n} ; \lim _{n \rightarrow \infty} T^{p} f x_{2 n}=f z=\lim _{n \rightarrow \infty} f T^{p} x_{2 n} \\
\left.\lim _{n \rightarrow \infty} x_{2 n+2}=\lim _{n \rightarrow \infty} g x_{2 n+1} ; \lim _{n \rightarrow \infty} S^{p} g x_{2 n+1}=\lim _{n \rightarrow \infty} g S^{p} x_{2 n+1}=g z\right] .
\end{gathered}
$$

Applying (14) by using for all posible cases of above conditions, we obtain

$$
p\left(T^{p} f x_{2 n}, S^{p} g x_{2 n+1}\right) \leq a\left[p\left(S^{p} x_{2 n}, T^{p} f x_{2 n}+p\left(T^{p} x_{2 n+1}, S^{p} g x_{2 n+1}\right)\right] .\right.
$$

On taking limit as $n \rightarrow \infty$, we have

$$
\begin{gathered}
p(f z, g z) \leq a[p(z, f z)+p(z, g z)] \\
p(f z, g z) \leq a[p(f z, g z)]
\end{gathered}
$$

which is a contradiction. Hence from $\left(p_{1}\right) ; p(f z, g z)=0$, which implies that

$$
f z=g z \text {. }
$$

Again, applying (14) and using condition (19), we get

$$
p\left(T^{p} f x_{2 n}, S^{p} g x_{2 n+1}\right) \leq a\left[p\left(S^{p} x_{2 n}, T^{p} f x_{2 n}\right)+p\left(T^{p} x_{2 n+1}, S^{p} g x_{2 n+1}\right)\right] .
$$

On taking limit as $n \rightarrow \infty$, we have

$$
\begin{gathered}
p(f z, z) \leq a[p(z, f z)+p(z, f z)] \\
p(f z, z) \leq 2 a[p(z, f z)],
\end{gathered}
$$

which is a contradiction. Hence from $\left(p_{1}\right) ; p(f z, z)=0$, which implies that $f z=z$. Applying (14) and using condition (19), we have

$$
p\left(T^{p} f x_{2 n}, S^{p} g x_{2 n+1}\right) \leq a\left[p\left(S^{p} x_{2 n}, T^{p} f x_{2 n}\right)+p\left(T^{p} x_{2 n+1}, S^{p} g x_{2 n+1}\right)\right]
$$

On taking limit as $n \rightarrow \infty$, we have

$$
\begin{gathered}
p\left(T^{p} z, S^{p} z\right) \leq a\left[p\left(z, T^{p} z\right)+p\left(z, S^{p} z\right)\right] \\
p\left(T^{p} z, S^{p} z\right) \leq a\left[p\left(T^{p} z, S^{p} z\right)\right],
\end{gathered}
$$

which is a contradiction. Hence by $\left(p_{1}\right), p\left(T^{p} z, S^{p} z\right)=0$; implies that

$$
T^{p} z=S^{p} z \text {. }
$$

Now, again applying (14), we have

$$
p\left(T^{p} f x_{2 n}, S^{p} g x_{2 n+1}\right) \leq a\left[p\left(S^{p} x_{2 n}, T^{p} f x_{2 n}\right)+p\left(T^{p} x_{2 n+1}, S^{p} g x_{2 n+1}\right)\right]
$$


On taking limit as $n \rightarrow \infty$, we have

$$
\begin{aligned}
& p\left(z, S^{p} z\right) \leq a\left[p\left(z, T^{p} z\right)+p\left(z, S^{p} z\right)\right], \\
& p\left(z, S^{p} z\right) \leq a\left[p\left(z, S^{p} z\right)+p\left(z, S^{p} z\right)\right],
\end{aligned}
$$

$p\left(z, S^{p} z\right) \leq 2 a\left[p\left(z, S^{p} z\right)\right]<p\left(z, S^{p} z\right)$, a contradiction. Hence from $\left(p_{1}\right), p\left(z, S^{p} z\right)=$ 0 , we get

$$
S^{p} z=z
$$

Therefore, $f, g, T^{p}$ and $S^{p}$ have common fixed point $z$. Now, we shall prove that common fixed point is unique. Suppose that the set of common fixed points of $f, g, T^{p}$ and $S^{p}$ are well ordered, we claim that common fixed point of $f, g, T^{p}$ and $S^{p}$ is unique.

Assume to contrary that $f u=u, g u=u, T^{p} u=u, S^{p} u=u$ and $f v=$ $v, g v=v, T^{p} v=v, S^{p} v=v$. Suppose $u \neq v$. Then, from (14), we have

$$
\begin{gathered}
p\left(T^{p} f u, S^{p} g v\right) \leq a\left[p\left(S^{p} u, T^{p} f u\right)+p\left(T^{p} v, S^{p} g v\right)\right] \\
p\left(T^{p} u, S^{p} v\right) \leq a\left[p\left(u, T^{p} u\right)+p\left(v, S^{p} v\right)\right] \\
p(u, v) a[p(u, u)+p(v, v)] .
\end{gathered}
$$

But from $\left(p_{2}\right)$; we have $p(u, u) \leq p(u, v)$, then (24) becomes

$$
\begin{gathered}
p(u, v) \leq a[p(u, v)+p(u, v)] \\
p(u, v) \leq 2 a p(u, v) .
\end{gathered}
$$

Which is a contradiction. Hence $p(u, v)=0$ implies $u=v$. Therefore $f, g, T$ and $S$ have unique fixed point. Conversely, if $f, g, T$ and $S$ have only one common fixed point i.e set of fixed points of $f, g, T$ and $S$ being a singleton then it is well ordered. Thus, the proof is completed.

Example 12.1. Let $X=[0,1] \cup\{2\}$ be a set with usual partial metric. Define functions such that

$$
\begin{aligned}
& f(x)= \begin{cases}0, \text { if } & x \in[0,1] \\
1, \text { if } & x=2\end{cases} \\
& g(x)= \begin{cases}0, \text { if } & x \in\left[0, \frac{1}{2}\right] \\
\frac{2}{3}, \text { if } & x=2\end{cases} \\
& S(x)= \begin{cases}0, \text { if } & x \in[0,1] \\
\frac{1}{2}, \text { if } & x=2\end{cases}
\end{aligned}
$$




$$
T(x)=0 \text {; when } x \in[0,1] \cup\{2\} .
$$

Here $T[0,1]=0, T(2)=0$, we get $T^{2}(x)=T^{3}(x)=\cdots=T^{p}(x)=0$; for all $x$ and $S[0,1]=0, S(2)=\frac{1}{2}$, we get $S^{2}(x)=S^{3}(x)=\cdots=S^{p}(x)=0$; for every $x$. We have $T f x=T[f[0,1]]=T[0]=0, T[f[2]]=T(1)=0$. Therefore, $T^{2} f x=T^{3} f x=T^{4} f x=\cdots=T^{p} f x=0$, for every $x$.

Similarly, $S g x=S[g[0,1]]=S[0]=0, S[g[2]]=S\left(\frac{2}{3}\right)=0$. Therefore, $S^{2} g x=S^{3} g x=S^{4} g x=\cdots=S^{p} g x=0$, for every $x$.

Let $x=0$ and $y=1$. Applying (14); we have

$p\left(T^{p} f(0), S^{p} g(1)\right) \leq a\left[p\left(S^{p}(0), T^{p} f(0)\right)+p\left(T^{p}(1), S^{p} g(1)\right], p(0,0) \leq a[p(0,0)+\right.$ $p(0,0)] \Rightarrow 0 \leq 0$. So, Theorem (3.8) is verified and we get $f, g, T^{p}$ and $S^{p}$ have a common fixed point 0 . Consiquently $f, g, T$ and $S$ have a unique common fixed point 0 .

Corollary 13. Let $(X, p, \preceq)$ be a 0-complete ordered partial metric space. Let $f, g, T$ and $M: X \rightarrow X$ be four maps satisfying

$$
p\left(T^{p} f x, S^{p} g y\right) \leq a\left[p\left(x, T^{p} f x\right)+p\left(y, S^{p} g y\right)\right]
$$

for all comparable $x, y \in X$. Where $a \in\left(0, \frac{1}{2}\right)$ and $p$ is some positive integer. We assume that

(i) $f, g, T$ and $S$ are continuous.

(ii) $f(X) \subseteq T(X)$ and $g(X) \subseteq S(X)$.

(iii) Pair $\left(f, T^{p}\right)$ and $\left(g, S^{p}\right)$ are weakly compatible.

Then $f, g, T$ and $S$ have a common fixed point.

Corollary 14. Let $(X, p, \preceq)$ be a 0-complete ordered partial metric space. Let $f, g, T$ and $M: X \rightarrow X$ be four maps satisfying

$$
p\left(T^{p} f x, S^{p} g y\right) \leq a\left[p\left(f x, T^{p} f x\right)+p\left(g y, S^{p} g y\right)\right]
$$

for all comparable $x, y \in X$. Where $a \in\left(0, \frac{1}{2}\right)$ and $p$ is some positive integer. We assume that

(i) $f, g, T$ and $S$ are continuous.

(ii) $f(X) \subseteq T(X)$ and $g(X) \subseteq S(X)$.

(iii) Pair $\left(f, T^{p}\right)$ and $\left(g, S^{p}\right)$ are weakly compatible.

Then $f, g, T$ and $S$ have a common fixed point.

\section{References}

[1] I. Altun, O. Acar, Fixed point theorems for weak contractions in the sense of Berinde on partial metric spaces. Topol. Appl. 159, (2012), 2642-2648. 
[2] I. Altun, F. Sola, H. Simsek, Generalized contractions on partial metric spaces. Topol. Appl. 157, (2010), 2778-2785.

[3] S. Banach, Sur les oprations dans les ensembles abstraits et leur applicationaux quations intgrales, Fundamenta Mathematicae, vol. 3, (1922) pp. 133-181.

[4] G. Jungck, Compatible mappings and common fixed points. Internat. J. Math. Math. Sci. 9 (1986), no.4,771-779.

[5] G. Jungck, Commuting mappings and fixed points. Amer. Math. Monthly 83 (1976) no.4,261-263.

[6] G. Jungck, Common fixed points for commuting and compatible maps on compacta. Proc. Amer. Math. Soc. 103 (1988), no. 3, 977-983.

[7] S. G. Matthews, Partial metric topology. Proc. 8th Summer Conference on Topology and its Applications. Ann. New York Acad. Sci. vol. 728, (1994), pp. 183-197.

[8] H. K. Nashine, I. Altun, Fixed point theorems for generalized weakly contractive condition in ordered metric spaces. Fixed Point Theory Appl. 2011 , Article ID 132367.

[9] H. K. Nashine, B. Samet, C. Vetro, Monotone generalized nonlinear contractions and fixed point theorems in ordered metric spaces. Math. Comput. Model. 54, (2011), 712720 .

[10] H. K. Nashine, Z. Kadelburg, S. Radenovic, Common fixed point theorems for weakly isotone increasing mappings in ordered partial metric spaces. Math. Comput. Model. (2012), doi: 10.1016/j.mcm. 2011.12.019.

[11] J. J. Nieto, R. Rodrıguez-López, Contractive mapping theorems in partially ordered sets and applications to ordinary differential equations. Order 22, (2005), 223-239.

[12] S. Oltra, O. Valero, Banach's fixed point theorem for partial metric spaces. Rend. Ist. Mat. Univ. Trieste 36, (2004), 17-26.

[13] R. P. Pant, Common fixed points of non-commuting mappings. J. Math. Anal. Appl. 188 (1994), 436-440.

[14] R. P. Pant, Common fixed points for four mappings. Bull. Calcutta Math. Soc. 90 (1998) no. 4, 281-286.

[15] Ran, ACM, Reurings, MCB: A fixed point theorem in partially ordered sets and some applications to matrix equations. Proc. Am. Math. Soc. 132, (2004), 1435-1443.

[16] B. E. Rhoades, A comparison of various definitions of contractive mappings. Trans. Am. Math. Soc. 336, (1977), 257-290.

[17] S. Romaguera, A Kirk type characterization of completeness for partial metric spaces. Fixed Point Theory Appl. 2010, Article ID 493298 (2010), doi: 10.1155/2010/493298.

[18] S. P. Singh, Some results on fixed point theorems, Yokohama Math. J. (1969), 6164.MR41.

[19] S. L. Singh, A. Tomar, Weaker forms of commuting maps and existence of fixed points, J. Korea Soc. Math. Educ. B: Pure Appl. Math. Volume 10 (3) (2003), 145-161.

[20] O. Valero, On Banach fixed point theorems for partial metric spaces. Appl. Gen. Topol. 6, (2005), 229-240. 